\title{
ANTENNAL ELECTROPHYSIOLOGICAL RESPONSES OF THREE PARASITIC WASPS TO CATERPILLAR-INDUCED VOLATILES FROM MAIZE (Zea mays mays), COTTON (Gossypium herbaceum), AND COWPEA (Vigna unguiculata)
}

\author{
SANDRINE GOUINGUENÉ, ${ }^{1,3, *}$ JOHN A. PICKETT, ${ }^{1}$ \\ LESTER J. WADHAMS, ${ }^{1}$ MICHAEL A. BIRKETT, ${ }^{1}$ \\ and TED C. J. TURLINGS ${ }^{2}$ \\ ${ }^{1}$ BCH Division, Rothamsted Research, Harpenden, Hertfordshire, AL5 2JQ, UK \\ ${ }^{2}$ Institute of Zoology, Laboratory of Animal Ecology and Entomology, \\ University of Neuchâtel, C. P. 2, CH-2007 Neuchâtel, Switzerland
}

(Received October 22, 2004; accepted January 10, 2005)

\begin{abstract}
Many parasitic wasps are attracted to volatiles that are released by plants when attacked by potential hosts. The attractiveness of these semiochemicals from damaged plants has been demonstrated in many tritrophic systems, but the physiological mechanisms underlying the insect responses are poorly understood. We recorded the antennal perception by three parasitoids (Cotesia marginiventris, Microplitis rufiventris, and Campoletis sonorensis) to volatiles emitted by maize, cowpea, and cotton plants after attack by the common caterpillar pest Spodoptera littoralis. Gas chromatography-electroantennography (GC-EAG) recordings showed that wasps responded to many, but not all, of the compounds present at the physiologically relevant levels tested. Interestingly, some minor compounds, still unidentified, elicited strong responses from the wasps. These results indicate that wasps are able to detect many odorant compounds released by the plants. It remains to be determined how this information is processed and leads to the specific behavior of the parasitoids.
\end{abstract}

Key Words - GC-EAG, electrophysiology, Cotesia marginiventris, Microplitis rufiventris, Campoletis sonorensis, induced plant odor.

* To whom correspondence should be addressed. E-mail: sgouinguene@yahoo.com

3 Current address: Agroscope, FAW Wädenswil, Schloss, Postfach 185, CH-8820, Wädenswil, Switzerland. 


\section{INTRODUCTION}

Many plants attacked by herbivorous insects indirectly defend themselves by emitting semiochemicals that act as attractants for natural enemies of the attackers (Dicke and Sabelis, 1988; Turlings et al., 1990; Steinberg et al., 1993; Agelopoulos and Keller, 1994; Geervliet et al., 1994; Röse et al., 1997; Du et al., 1998; Shiojiri et al., 2000; Neveu et al., 2002). At least 12 families of plants produce volatiles in response to herbivory (Dicke, 1999). The compositions of the volatiles produced are variable, but isoprenoids, lipoxygenase-derived volatiles, and aromatics (derived from either the phenylalanine-ammonia-lyase pathway or from other amino acids) commonly dominate the blends released by insect-damaged plants (Whitman and Eller, 1990; Tumlinson et al., 1992; Rutledge, 1996). The emission of volatiles after attack by Lepidoptera is induced by elicitors in the oral secretions of herbivores (Dicke et al., 1993; Turlings et al., 1993; Mattiacci et al., 1995). Two different types of elicitors have been identified, a $\beta$-glucosidase from Pieris rapae (Lepidoptera: Pieridae) (Mattiacci et al., 1995), and fatty acid derivatives, such as volicitin isolated from Spodoptera exigua (Lepidoptera: Noctuidae) (Alborn et al., 1997; Turlings et al., 2000).

Spodoptera spp. (Lepidoptera: Noctuidae) larvae are important pests of various cultivated plants, including maize (Zea mays mays), cotton (Gossypium herbaceum), and cowpea (Vigna unguiculata). In response to larval feeding, these plants emit a particular odor (Turlings, 1990; McCall et al., 1993; Röse et al., 1996) that is perceptible even by humans (Gouinguené, personal observation). These pests can be parasitized by various wasps, including Cotesia marginiventris (Hymenoptera: Braconidae), Microplitis rufiventris (Hymenoptera: Braconidae), and Campoletis sonorensis (Hymenoptera: Ichneumonidae). The induced odors emitted by maize, cotton, and cowpea plants during feeding by Spodoptera spp. are attractive to each of these parasitoids (Turlings et al., 1995; Röse et al., 1998; C. Tamó and T. Degen, personal communication). According to the species of plant, the induced odor can vary, although some common substances are present in the different blends (Turlings et al., 1991; Röse et al., 1998; Hoballah et al., 2002). C. marginiventris and $C$. sonorensis originate from the new world, while $M$. rufiventris occurs in the old world, in particular in north Africa. These are generalists, although $M$. rufiventris is found more often parasitizing $S$. littoralis feeding on cotton plants (C. Tamó, personal communication). The different hosts of these parasitoids are often generalists, and feed on various plant families, including maize, cotton, and cowpea.

Although the responses of parasitoids to induced plant odors have been intensively studied in terms of behavior, the physiological mechanisms underlying the behavior are largely unknown. Coupled high-resolution gas chromatog- 
raphy (GC) and electrophysiology techniques can be used to identify physiologically active compounds from complex natural product extracts (Wadhams, 1990). This approach has been used to determine active components in the odor blend of maize for C. flavipes, a parasitoid of the stemborer spp (Ngi-Song and Overholt, 1997). Female $C$. flavipes respond to six compounds (an unidentified $\mathrm{C}_{5}$ compound, heptanal, $(Z)$-3-hexenyl acetate, $(E)$-ocimene, linalool, and $(E)$ 4,8-dimethyl-1,3,7-nonatriene (DMNT)) in the odor of maize infested with Chilo partellus larvae (Lepidoptera: Pyralidae). Using simple EAG recordings, $C$. sonorensis has been shown to respond to green leaf volatiles, monoterpenes ( $\alpha$-pinene, myrcene, limonene), and with lower sensitivity to sesquiterpenoids (gossonorol, $\beta$-caryophyllene oxide, $\beta$-caryophyllene, $\alpha$-humulene) (Baehrecke et al., 1989). So far, no data are available on the perception of induced odor by C. marginiventris and M. rufiventris. EAG recordings have also been used to test the sensitivity of antennal perception in some other parasitoids (Lecomte and Pouzat, 1985; Salom et al., 1991; Jyothi et al., 2002). Only a few studies on parasitoids have been done using coupled GC and EAG systems. Pettersson et al. (2000) found that the bark beetle parasitoid, Rotrocerus xylophagum (Hymenoptera: Pteromilidae), did not respond to the major compounds present in the bark oil. More recently, Smid et al. (2002) compared the responses of a specialist and generalist parasitoid of Pieris caterpillar to attacked Brussels sprouts, and showed that the two parasitoid species responded similarly to a large number of compounds present in the odor of damaged plants. Interestingly, two compounds were only perceived by the specialist parasitoid (Cotesia rubecula) (Smid et al., 2002).

The aim of this study was to use the GC-EAG approach to determine and to compare the antennal perception of compounds in the induced odor blends of maize, cotton, and cowpea for the three generalist parasitoids C. marginiventris, $M$. rufiventris, and $C$. sonorensis, which show strong similarities in host range and life cycle.

\section{METHODS AND MATERIALS}

Insects. C. marginiventris, M. rufiventris, and C. sonorensis were provided by the Laboratory of Animal Ecology and Entomology, University of Neuchâtel, Switzerland. The rearing of the three parasitoids follows the same procedure. Second instar larvae of $S$. littoralis were exposed to female parasitic wasps for at least $2 \mathrm{hr}$, then wasps were removed and the larvae reared on artificial diet (Syngenta, Basel, Switzerland). When the parasitic larvae are ready to pupate, they exit the host and form cocoons that can be easily collected. Cocoons were placed in plastic boxes $(13.5 \times 7.5 \times 6 \mathrm{~cm})$ with wet cotton to 
maintain humidity and drops of honey for food. Newly-emerged adult parasitoids were sexed, and placed in plastic cups $(6.5 \times 5.5 \mathrm{~cm}$ diam. $)$, and were provided with honey and wet cotton. They were kept in a climate chamber $\left(20^{\circ} \mathrm{C}, 40 \% \mathrm{RH}\right)$ and 2 - to 3 -d-old females were used in experiments.

Collection of Induced Odors. Air entrainment samples of induced odor of cotton, maize (variety Delprim), and cowpea were used, and were prepared at the University of Neuchâtel. Three seeds of cotton, maize, and cowpea were sown in plastic pots, filled with fertilized potting soil (Coop, Switzerland). Plants were grown in a climate chamber at $23^{\circ} \mathrm{C}, 60 \% \mathrm{RH}$, and under $50,000 \mathrm{~lm} / \mathrm{m}^{2}$ (16L:8D). Fifteen-d-old plants were used. To induce the plants to emit volatiles, $30 \mathrm{~S}$. littoralis larvae (second instar) were allowed to feed on the three plant species for $2 \mathrm{~d}$ prior to the first odor collection. The volatile collection system has been described in detail (Turlings et al., 1998) and was modified as follows. It consisted of five vertically placed glass cylinders ( $7 \mathrm{~cm}$ i.d., $43 \mathrm{~cm}$ high). The pot with the three plants was placed in a glass pot $(7 \mathrm{~cm}$ diam., $8.5 \mathrm{~cm}$ high), which fits in the vertical cylindrical glass. Purified and humidified air was pushed into each cylinder at a rate of $1 \mathrm{l} / \mathrm{min}$ and flowed around the plant. Around the base of each cylinder, an opening served as a port that could hold the collection traps. For collections, air was drawn $(0.8 / \mathrm{min})$ through a Super-Q adsorbent trap (Heath and Manukian, 1994), while the rest of the air vented through the hole in the top, thus preventing external, impure air from entering. The automated part of the collection system (Analytical Research System, Gainesville, FL, USA) controlled flow through the trap. The climate chamber (CMP4030, CONVIRON, Winnipeg, Canada) in which the collection cylinders were housed was kept at $17.5^{\circ} \mathrm{C}$. Due to the heat irradiation, the temperature inside the cylinders was $23 \pm 3^{\circ} \mathrm{C}$. During the photophase (16L:8D) light intensity was approx. $20,000 \mathrm{~lm} / \mathrm{m}^{2}$.

Two collections were done during the day, starting 2 and $9 \mathrm{hr}$ after the beginning of the photophase. Each collection lasted $6 \mathrm{hr}$. After each collection, traps were extracted with $250 \mu \mathrm{l}$ of methylene chloride (Lichrosolv, Merck, Switzerland). The same plants were used for volatile collection the next day. At the end of the $2 \mathrm{~d}$, the samples from the four collections of the same plant species were pooled. To obtain control samples, the same conditions were used to collect volatiles from undamaged plants, pot and soil only, and empty glasses.

Electrophysiology. Electroantennogram (EAG) recordings from 2- to 3-dold female wasps were made using $\mathrm{Ag}-\mathrm{AgCl}$ glass electrodes filled with saline solution (composition as Maddrell (1969), without glucose). The insect was anaesthetized by chilling, and the head was excised and inserted in the tip of the indifferent electrode. The tips of the two antennae were inserted into the recording electrode. Signals were passed through a high impedance amplifier 
(UN-06, Syntech, The Netherlands) and analyzed by using a customized software package (Syntech, The Netherlands).

Coupled Gas Chromatography-Electroantennography (GC-EAG). The coupled GC-EAG system, in which the effluent of the GC column is simultaneously directed to the antennal preparation and the GC detector, has been described (Wadhams, 1990). Separation of the volatiles was achieved on an AI 93 GC equipped with a cold on-column injector and an FID. The column used was a $50 \mathrm{~m} \times 0.32 \mathrm{~mm}$ i.d. HP-1 column (non polar). Oven temperature was maintained at $40^{\circ} \mathrm{C}$ for $2 \mathrm{~min}$ and then programmed at $5^{\circ} \mathrm{C} / \mathrm{min}$ to $100^{\circ} \mathrm{C}$ and then at $10^{\circ} \mathrm{C} / \mathrm{min}$ to $250^{\circ} \mathrm{C}$. The carrier gas was hydrogen $(15 \mathrm{psi})$. The outputs from the EAG amplifier and the FID were monitored simultaneously and analyzed with the software package (Syntech, the Netherlands). A standard stimulation was done at the beginning and at the end of each recording to correct for the loss of sensitivity of the preparation. The stimulus (100 $\mu \mathrm{g}$ of $(Z)$-3-hexenol) was applied on a filter paper strip, inserted in a Pasteur pipette, and a puff of odor was flushed on the EAG preparation. For the correction, we assumed that the decrease in sensitivity is linear with the time. Data were then normalized to the standard as follows:

$$
\frac{A}{\mathrm{EAG}(\operatorname{std} 1)+(\mathrm{EAG}(\mathrm{std} 2)-\mathrm{EAG}(\operatorname{std} 1)) \frac{\mathrm{RT}(\mathrm{A})-\mathrm{RT}(\operatorname{std} 1)}{\mathrm{RT}(\operatorname{std} 2)-\mathrm{RT}(\operatorname{std} 1)}}
$$

where $A$ is the amplitude (mV) of the EAG response to compound $A$; EAG(std1) is the EAG response to standard at the beginning of the recording; EAG(std2) is the EAG response to standard at the end of the recording; RT(A) is the retention time of compound $A ; \mathrm{RT}(\operatorname{std} 1)$ is the time when the stimulation at the beginning of the recording was done; RT(std2) denotes the time when the stimulation at the end of the recording was done. For each induced odor tested, responses from 10 females were recorded.

Coupled Gas Chromatography-Mass Spectrometry (GC-MS). GC-MS was used to tentatively identify compounds giving rise to the peaks associated with EAG activity from the induced odor blend of maize, cowpea, and cotton. A capillary GC column $(50 \mathrm{~m} \times 0.32 \mathrm{~mm}$ i.d. HP-1) fitted with a cold on-column injector was directly coupled to a mass spectrometer (VG Autospec, Fisons Instruments). Ionization was by electron impact at $70 \mathrm{eV}, 250^{\circ} \mathrm{C}$. The oven temperature was maintained at $30^{\circ} \mathrm{C}$ for $5 \mathrm{~min}$ and then programmed at $5^{\circ} \mathrm{C} / \mathrm{min}$ to $250^{\circ} \mathrm{C}$. Peak identities were determined by comparison of the spectra with those of authentic compounds from synthesis or other botanical sources and confirmed by comparison of Kovat's indices.

Statistical Analysis. Normalized EAG responses of the three parasitoids to the different plants odor were compared using nonparametric tests. On each compound that activated a response from the parasitic wasps, a Kruskall-Wallis 
comparison was done, when it was shown that the mean responses were different, Mann-Whitney pairs comparisons were realized to determine which parasitoid was different from which. For such comparison, the level of significativity was corrected using the Bonferroni correction, thus $\alpha=0.017$.

\section{RESULTS}

Figures 1, 2, and 3 present representative GC-EAG recordings from the 10 replicates from each wasp species and each induced odor (60 recordings in total). Most of the major compounds elicited EAG responses from the three parasitoids. Some minor compounds also evoked strong responses (Figures 1, 2, and 3). The greatest responses were obtained from the green leaf volatiles ( peaks a, b, n), whereas lower responses were recorded later in the GC-EAG analytical traces. This difference may reflect a differences in sharpness of the GC peaks and the number of molecules that hit the antennae at the same time and should not be interpreted as difference in strength of perception. Table 1

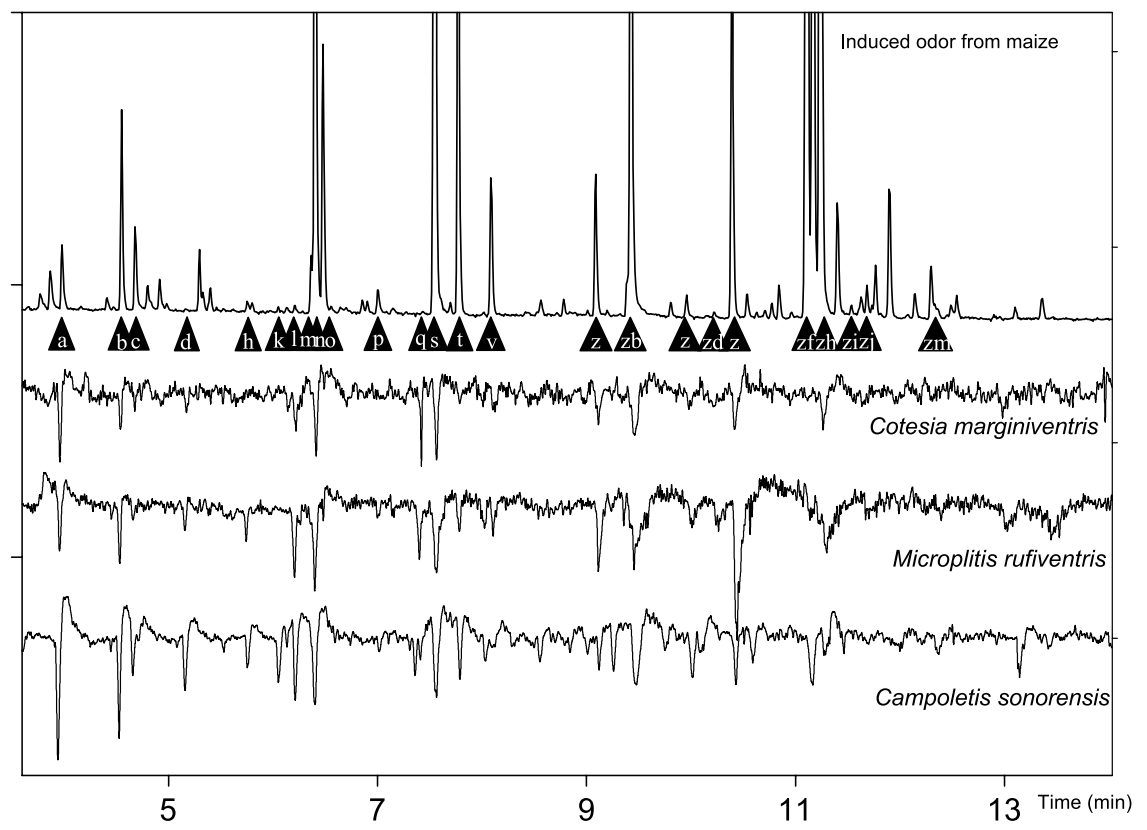

FIG. 1. GC-EAG traces of Cotesia marginiventris, Microplitis rufiventris and Campoletis sonorensis in response to the caterpillar-induced odor from maize. 


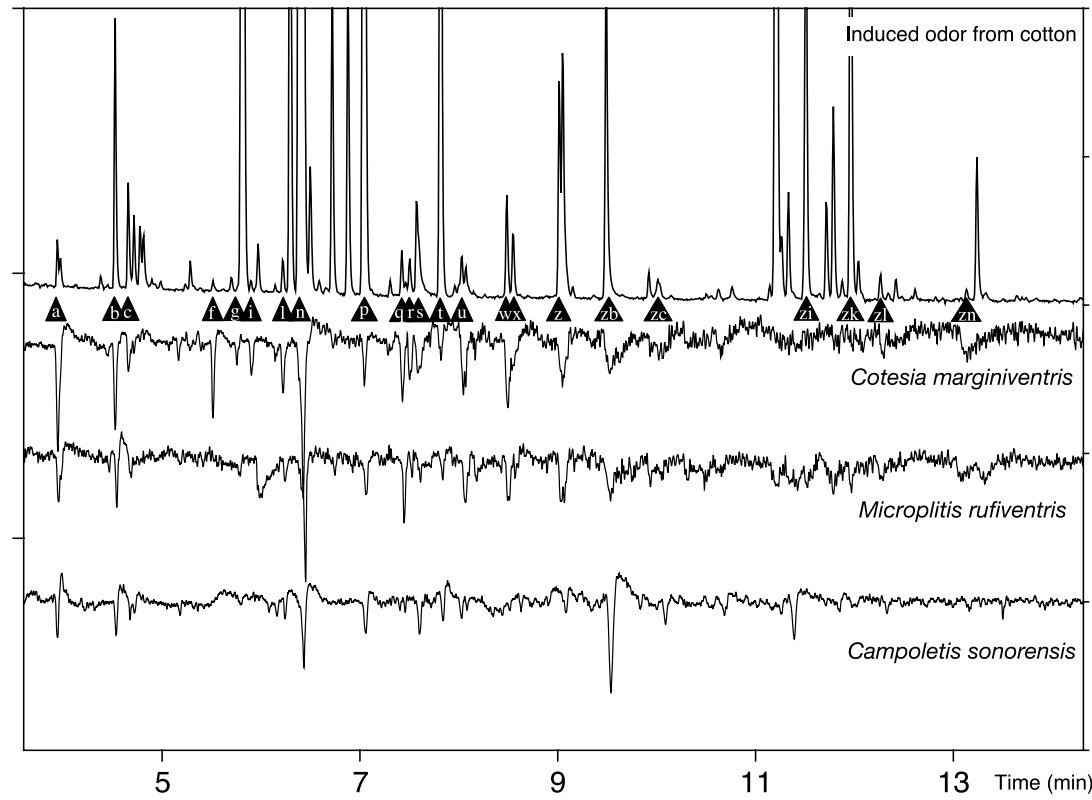

FIG. 2. GC-EAG traces of Cotesia marginiventris, Microplitis rufiventris and Campoletis sonorensis in response to the caterpillar-induced odor from cotton.

gives the identity and normalized EAG value of all the electrophysiologically active compounds in the three induced odor samples tested. The letter in the first column refers to the letters in Figures 1, 2, and 3. Only a few small responses were recorded from the volatile samples from undamaged control plants (Figure 4). For example, in odor from undamaged maize, these responses were associated with the constitutive compounds, like linalool (s).

For maize, a total of 25 compounds in the induced blend gave detectable responses from the three parasitoids combined (Figure 1 and Table 1). EAG responses from $C$. marginiventris were elicited by 24 compounds. $C$. sonorensis females responded to 20 compounds (Figure 1). C. marginiventris showed high responses to (E)-2-hexenal (b), (Z)-3-hexenyl acetate (n), linalool (s), neryl or geranyl acetate (ze), and unknown 5 (l) (Table 1). Normalized responses to $(E)$ 2-hexenal (b) were higher than the response of the two other parasitic wasps (comparison with $M$. rufiventris, $P=0.004$; with $C$. sonorensis, $P=0.005$ ), while responses to DMNT were lower ( $P=0.005$ in both comparisons). Neryl or geranyl acetate (ze) gave the highest response (20.6\%) from M. rufiventris (Table 1), and that response was significantly higher than the one from C. sonorensis $(P=0.007)$. M. rufiventris responded weakly to unknown 5 (1) as 


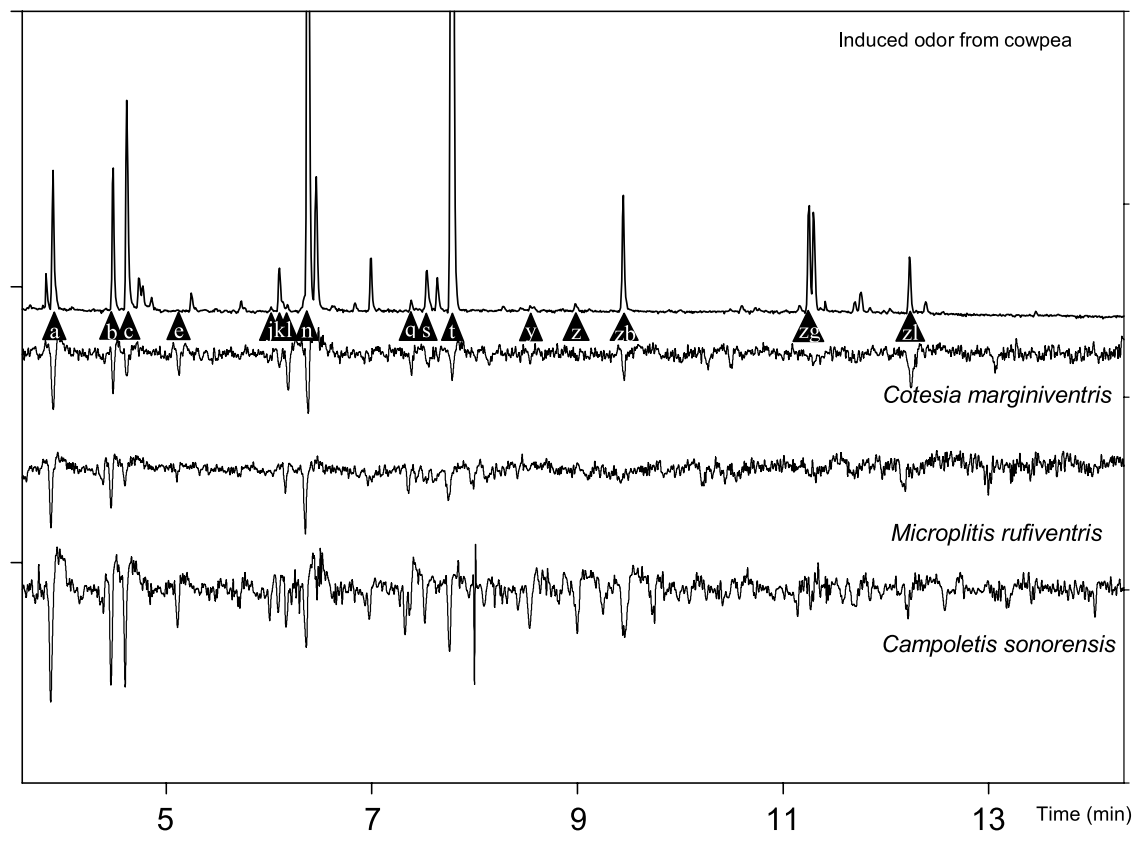

FIG. 3. GC-EAG traces of Cotesia marginiventris, Microplitis rufiventris and Campoletis sonorensis in response to caterpillar-induced odor from cowpea.

compared to $C$. marginiventris $(P<0.001)$ and $C$. sonorensis $(P<0.001)$. $C$. sonorensis showed higher responses to linalool (s), (Z)-3-hexenyl acetate (n), (Z)-3-hexenol (f), (Z)-3-hexenal (a), and DMNT (t). C. sonorensis had lower responses than $C$. marginiventris to $(E)$-2-hexenal (b) $(P=0.005)$. Although not statistically different, responses to methyl anthranilate $(\mathrm{zc})$ by $C$. sonorensis tended to be low compared to the ones of the two other parasitoids. Benzyl acetate (v) evoked no responses in C. sonorensis. Interestingly, all three parasitoids responded strongly to geranyl acetate (ze).

A total of 23 compounds were perceived in the induced odor of cotton (Figure 2). As in maize plants, some of the minor compounds elicited relatively strong EAG responses in C. marginiventris (i and 1, Figure 2). C. sonorensis and $C$. marginiventris appeared to have similar sensitivity to most of the compounds from induced odor of cotton. These wasps showed a greater sensitivity to green leaf volatiles (compounds a, b, and c) than M. rufiventris (Figure 2 and Table 1), which had significantly lower response to $(Z)-3$-hexen-1-ol (c) ( $P=0.015$ and $P=0.01$, respectively). Compared to the other two wasps, $C$. marginiventris showed particularly strong responses to methyl-(Z)-3-hexa- 

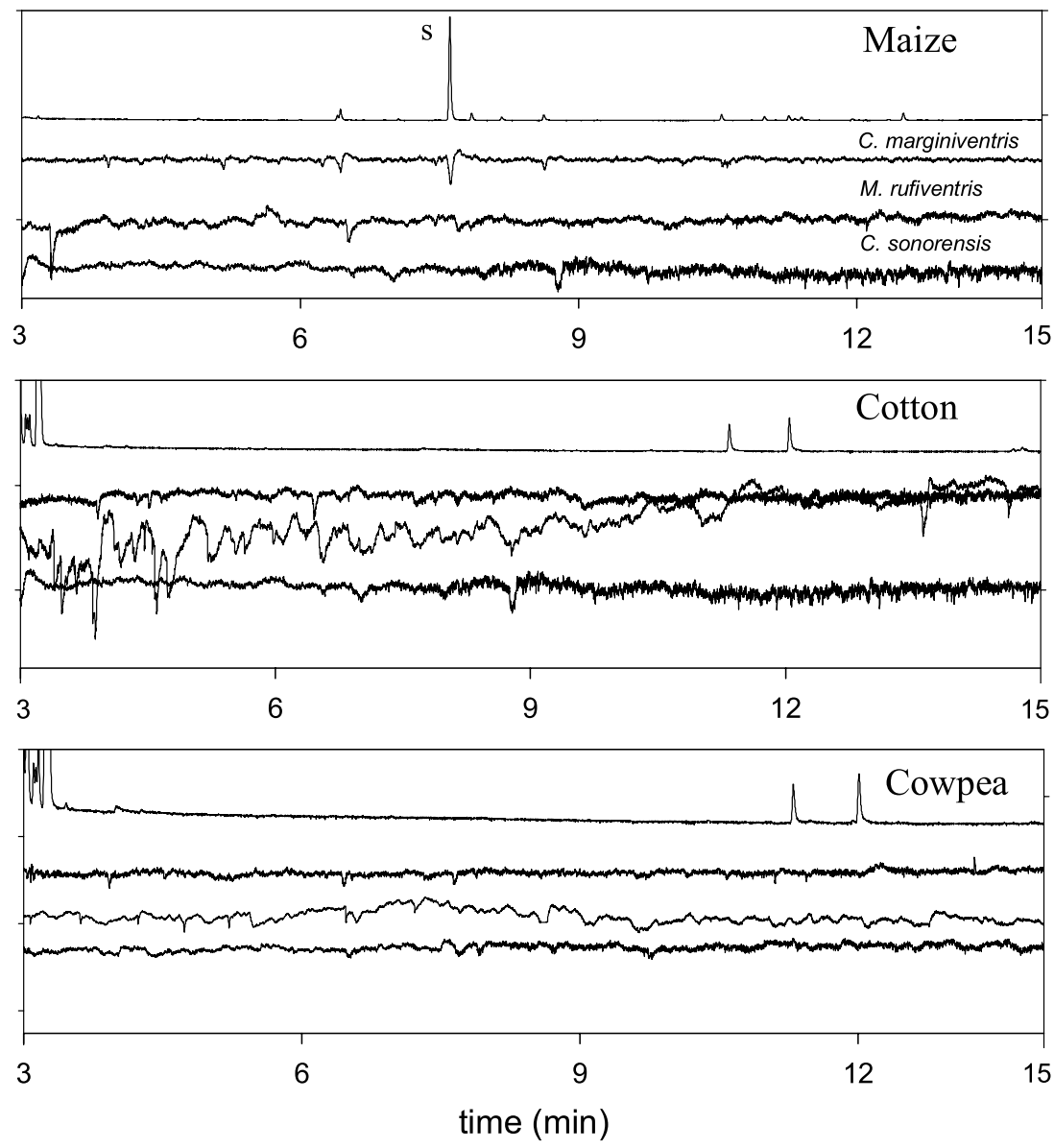

FIG. 4. GC-EAD traces of Cotesia marginiventris, Microplitis rufiventris and Campoletis sonorensis in response to odor from undamaged cotton, maize and cowpea.

noate (f) $(P<0.001$ both with $M$. rufiventris and $C$. sonorensis), nerolidol (zl), and unknown 8 (zn) (although not significantly different). M. rufiventris was less responsive to $(Z)$-3-hexen-1-ol (c), methyl benzoate $(\mathrm{q})$, and DMNT (t) compared to $C$. marginiventris $(P=0.015, P=0.001, P=0.011$, respectively) and $C$. sonorensis except to DMNT $(P=0.010, P<0.001, P=0.043)$. $M$. rufiventris did not respond to unknown 3 (i), unknown 5 (1), or humulene (zi).

The induced blend of cowpea was less complex than those from maize and cotton (Figure 3). Only 16 compounds elicited EAG responses from the parasitoids (Figure 3). For all parasitoids, responses to green leaf volatiles were 


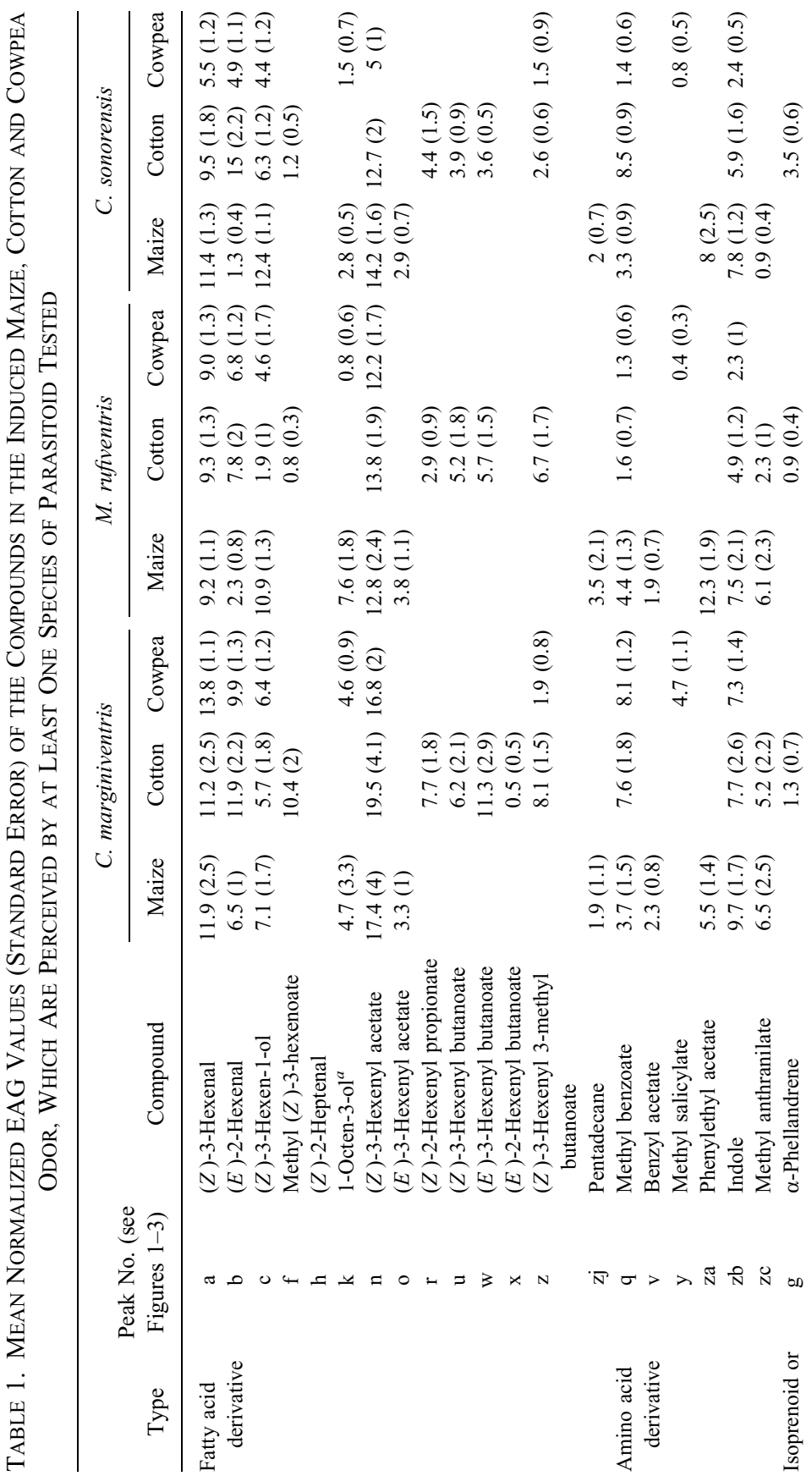



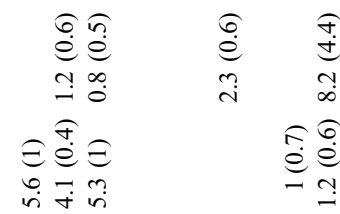

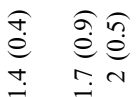

$\stackrel{0}{0}$

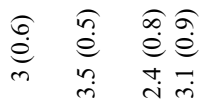

กิกิ

éd

o.

ลิ

Эิ

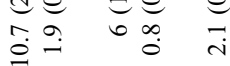

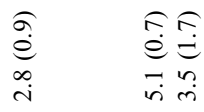

$\stackrel{n}{=}=$

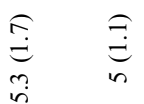

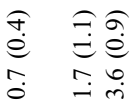

$\stackrel{\infty}{\infty} \hat{e}$

అ

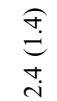

בิ

ํे

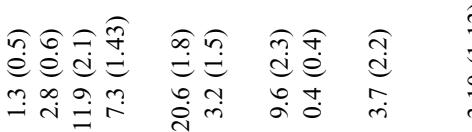

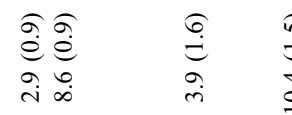

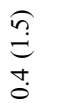

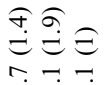

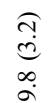

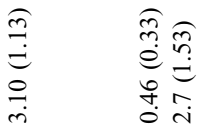

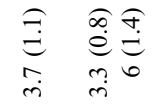

ì

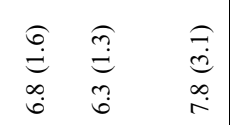

กิ่ $\widehat{x} \phi$

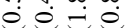

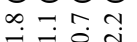

กิ่

ก) 6

$\stackrel{\infty}{i} \underset{1}{i}$

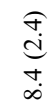

ఠิ

$\stackrel{f}{\Xi}$

$\mathrm{di}=$

तั

\section{䆓苋}

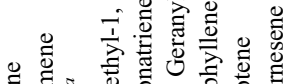

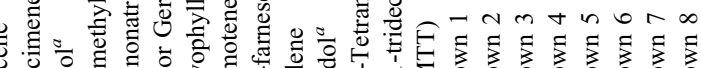

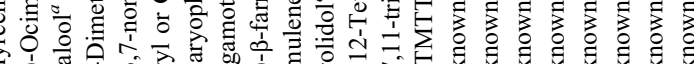

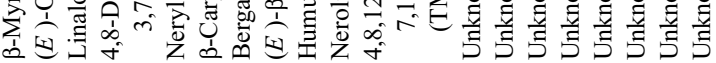

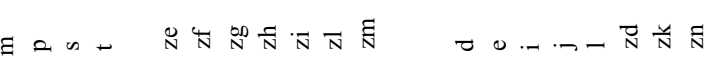


dominant, but $C$. marginiventris also responded relatively well to nerolidol (zl) and methyl benzoate (q) $(P<0.001$ for both M. rufiventris and C. sonorensis) (Figure 3). C. marginiventris showed a tendency to higher responses compared to the two other parasitoids (Table 1), while M. rufiventris and C. sonorensis responded similarly to the compounds in cowpea induced odor (Table 1). C. sonorensis responded significantly with lower intensity to DMNT (t) $(P<$ $0.001)$, while responses from $C$. marginiventris and $M$. rufiventris were not different $(P=0.72)$. Some compounds did not activate the olfactory receptors, even when released in large amounts. The most striking example was $\alpha$-pinene (peak between $g$ and i) in the induced cotton odor (Figure 2). Again, all three species were sensitive to some minor compounds (f, g, i, and l), which may be of importance in the recognition of specific host plants. In intact plants, the emission of volatiles was extremely low, which led to no activation of the olfactory receptors on wasps' antennae (Figure 4).

\section{DISCUSSION}

The release of volatile compounds when plants are attacked by insect herbivores, and the attractiveness of such induced compounds to natural enemies, have been shown in various studies (Turlings et al., 1990; Steinberg et al., 1993; Geervliet et al., 1994; Dicke and Vet, 1998). In some systems, there are key compounds for the attraction of parasitoids, such as 6-methyl-5-hepten-2-one, which is an indicator of the presence of specific host aphids for the parasitoid, Aphidius ervi (Du et al., 1998). In other systems, the role of the various compounds in the induced odor blends appears to be more complex (Dicke et al., 1990; Vet et al., 1990; Turlings et al., 1995; Röse et al., 1998). In this study, we compared the olfactory perception of three female parasitoids to the induced odor of maize, cotton, and cowpea to determine if there are key compounds mediating host location. The results showed that many, but not all, of the compounds in the induced odors were perceived by the parasitoids. There were some differences in the intensity of response to particular compounds, indicating potential differential sensitivity of the parasitoids to the various volatiles. For example, C. sonorensis and M. rufiventris both responded to linalool, but when the amount of this compound was reduced, as it is in the induced odor of cowpea, no EAG activity was detected, whereas C. marginiventris still responded at these concentrations. For an accurate determination of the response threshold of the different parasitoids, dose-response measurements should be made for each compound perceived and for each wasp. The absence of responses from odor blends of control plants indicates that the undetectable amount of odor released in the absence of attack by herbivorous insects may not 
be useful at long distance. It cannot be excluded, however, that undetectable amounts of specific plant odors may be detected at short distance. Although it is difficult to distinguish any specific pattern of response from the parasitoids due to the high number of EAG active compounds in the different blends tested, minor compounds may play a more important role than previously thought. The strong EAG responses elicited by these semiochemicals suggests this. While the major compounds are ubiquitous plant secondary metabolites, and may provide general information indicating herbivore-damaged plants, information on the identity of the herbivore doing the damage may be indicated by differences in ratios between the different compounds (De Moraes et al., 1998), and minor compounds may also be key in specific host recognition. Some of these minor compounds were not present in the odor of all three plants, being more plantthan host-specific.

No specific relation between the origin of female parasitoids and their preferred plant/host complex could be detected. For example, M. rufiventris, which occurs in Egypt, is more prevalent on cotton plants than the two other parasitoids (C. Tamò, personal communication), but this was not reflected in the antennal responses. It is also curious that, in general, the wasps showed relatively poor responses to DMNT, TMNT, and several sesquiterpenes, which are typical for caterpillar-induced odor blends and have been assumed to be key attractants. This poor perception of these compounds, however, corresponds well with results from behavioral assays designed to pinpoint key parasitoid attractants (Hoballah et al., 2002: M D'Alessandro, M. Held, T. Turlings, personal communication).

A recent study measured the olfactory responses of $C$. glomerata, a generalist parasitoid, and C. rubecula, a specialist parasitoid of Pieris rapae. No obvious differences were found in the detected range of compounds released by Brussels sprouts when attacked by caterpillars (Smid et al., 2002). This confirms the difficulty of detecting any differences in peripheral perception among parasitoids. As observed for the parasitoids in the present study, C. glomerata and C. rubecula show a broad olfactory capability responding to 20 compounds in the cabbage volatiles (Smid et al., 2002). The wasps' ability to detect a wide range of compounds in the induced odors of maize, cotton, and cowpea plants suggests that they use a wide range of compounds to identify plants that carry hosts. However, not all detected compounds are expected to have an effect on behavior. The attraction of female parasitoids could be due to a few specific compounds in the blend, or to a specific mixture of compounds. This is testable, as is the relative importance of the minor compounds on parasitoid behavior. Identification of the minor EAG active compounds in the different blends may reveal interesting prospects for application and should improve our understanding of the recognition by female parasitoids of plants attacked by potential hosts. More detailed study should be done at the single sensillum level in order 
to determine the specificity of olfactory cells to the different compounds present in the induced blends.

The results show that these parasitic wasps have a wide olfactory capability and that there is little difference among species of parasitoids. Further studies to understand the mechanisms mediating host location by parasitic wasps may help in developing methods to optimize the efficiency of natural enemies as biological control agents.

Acknowledgments-The authors thank Christine Woodcock for her help and advice on the GC-EAG system; Cristina Tamò, Liselore Roelfstra, and Yves Borcard for rearing the parasitoids at the University of Neuchâtel. Rothamsted Research receives grant-aided support from the Biotechnology and Biological Sciences Research Council (BBSRC) of the United Kingdom. This project was funded by the Swiss National Science Foundation, Young Scientist Fellowship.

\section{REFERENCES}

Agelopoulos, N. G. and Keller, M. A. 1994. Plant-natural enemy association in the tritrophic system, Cotesia rubecula-Pieris rapae-Brassicae (Cruciferae). I. Sources of infochemicals. J. Chem. Ecol. 20:1725-1748.

Alborn, H. T., Turlings, T. C. J., Jones, T. H., Stenhagen, G., Loughrin, J. H., and TUMLINSON, J. H. 1997. An elicitor of plant volatiles from beet armyworm oral secretion. Science 276:945-949.

BAEHRECKE, E. H., Williams, H. J., and Vinson, S. B. 1989. Electroantennogram responses of Campoletis sonorensis (Hymenoptera: Ichneumonidae) to chemicals in cotton (Gossypium hirsutum L.). J. Chem. Ecol. 15:37-45.

De Moraes, C. M., Lewis, W. J., Paré, P. W., Alborn, H. T., and Tumlinson, J. H. 1998. Herbivore-infested plants selectively attract parasitoids. Nature 393:570-573.

DICKE, M. 1999. Evolution of induced indirect defense of plants, pp. 62-88, in R. Tollrian and C. D. Harvell (eds.). The Ecology and Evolution of Inducible Defenses. Princeton University Press, Princeton.

Dicke, M. and SAbelis, M. W. 1988. How plants obtain predatory mites as bodyguards. Neth. J. Zool. 38:148-165.

Dicke, M. and Vet, L. E. M. 1998. Plant-carnivore interactions: Evolutionary and ecological consequences for plant, herbivore and carnivore, pp. 483-520, in H. Olff, V. K. Brown, and R. H. Drents (eds.). Herbivores: Between Plants and Predators. Blackwell Science, Oxford, UK.

Dicke, M., Van der MaAs, K., Takabayashi, J., and Vet, L. E. M. 1990. Learning affects response to volatile allelochemicals by predatory mites. Proc. Exp. Appl. Entom., N. E. V. Amsterdam 1:31-36.

Dicke, M., van BaARlen, P., Wessels, R., and Dikman, H. 1993. Herbivory induces systemic production of plant volatiles that attract predators of the herbivore: Extraction of endogenous elicitor. J. Chem. Ecol. 19:581-599.

Du, Y., Poppy, G. M., Powell, W., Pickett, J. A., Wadhams, L. J., and Woodcock, C. M. 1998. Identification of semiochemicals released during aphid feeding that attract parasitoid Aphidius ervi. J. Chem. Ecol. 24:1355-1368.

GeERVLiet, J. B. F., Vet, L. E. M., and Dicke, M. 1994. Volatiles from damaged plants as a major cues in long-range host searching by the specialist parasitoid Cotesia rubecula. Entomol. Exp. Appl. 73:289-297. 
Heath, B. and ManUKian, A. 1994. An automated system for use in collecting volatile chemicals released from plants. J. Chem. Ecol. 20:593-608.

Hoballah, M. E. F., TAmo, C., and TuRlingS, T. C. J. 2002. Differential attractiveness of induced odors emitted by eight maize varieties for the parasitoid Cotesia marginiventris: Is quality or quantity important? J. Chem. Ecol. 28:951-968.

Jyothi, K. N., Prasuna, A. L., Sighamony, S., Kumari, B. K., Prasad, A. R., and Yadav, J. S. 2002. Electroantennogram responses of Apanteles obliquae (Hym., Braconidae) to various infochemicals. J. Appl. Entomol. 126:175-181.

LeComte, C. and PouZAT, J. 1985. Réponses électroantennographiques de deux parasitoïdes Ichneumonidés, Diadromus pulchellus et $D$. collaris, aux odeurs de végétaux, du phytophagehôte Acrolepiopsis assectella et du partenaire sexuel. Entomol. Exp. Appl. 39:295-306.

MADDRELL, S. H. P. 1969. Secretion by the Malphigian tubules of Rhodnius. The movement of ions and water. J. Exp. Biol. 51:71-97.

Mattiacci, L., Dicke, M., and Posthumus, M. A. 1995. $\beta$-Glucosidase: An elicitor of herbivoreinduced plant odor that attracts host-searching parasitic wasps. Proc. Natl. Acad. Sci. U.S.A. 92:2036-2040.

MCCALl, P. J., TuRlings, T. C. J., Lewis, W. J., and Tumlinson, J. H. 1993. Role of plant volatiles in host location by the specialist parasitoid Microplitis croceipes Cresson (Braconidae: Hymenoptera). J. Insect Behav. 6:625-639.

Neveu, N., Grandgirard, J., Nenon, J. P., and Cortesero, A. M. 2002. Systemic release of herbivore-induced plant volatiles by turnips infested by concealed root-feeding larvae Delia radicum L. J. Chem. Ecol. 28:1717-1731.

NGi-Song, A. J. and Overholt, W. A. 1997. Host location and acceptance by Cotesia flavipes (Cameron) and C. sesamia (Cameron) (Hymenoptera: Braconidae), parasitoids of African gramineaous stemborers: Role of frass and other host cues. Biol. Contemp. 136-142.

Pettersson, E. M., Sullivan, B. T., Anderson, P., Berisford, C. W., and Birgersson, G. 2000. Odor perception in the bark beetle parasitoid Rotrocerus xylophagorum exposed to host associated volatiles. J. Chem. Ecol. 26:2507-2525.

RÖSE, U. S. R., MANUKIAN, A., HEATH, R. R., and TuMlinson, J. H. 1996. Volatile semiochemicals released from undamaged cotton leaves. A systemic response of living plants to caterpillar damage. Plant Physiol. 111:487-495.

Röse, U. S. R., Alborn, H. T., Makrancz, Y. G., Lewis, W. J., and Tumlinson, J. H. 1997. Host recognition by the specialist endoparasitoid Microplitis croceipes (Hymenoptera, Braconidae): role of host- and plant-related volatiles. J. Insect Behav. 10:313-330.

RösE, U. S. R., LEWIS, W. J., and TUMLINSON, J. H. 1998. Specificity of systemically released cotton volatiles as attractants for specialist and generalist parasitic wasps. J. Chem. Ecol. 24:303-319.

RUTLEDGE, C. E. 1996. A survey of identified kairomones and synomones used by insect parasitoids to locate and accept their hosts. Chemoecology 7:121-131.

Salom, S. M., Birgersson, G., PAYNe, T. L., and Berisford, C. W. 1991. Electroantennogram responses of the southern pine beetle parasitoid Dinotiscus dendroctoni (Ashmead) (Hymenoptera: Braconidae) to potential semiochemicals. J. Chem. Ecol. 17:2527-2538.

ShioJiRI, K., TAKABAYAShi, J., YANO, S., and TAKafuJi, A. 2000. Flight response of parasitoids toward plant-herbivore complexes: A comparative study of two parasitoid-herbivore systems on cabbage plants. Appl. Entomol. Zool. 35:87-92.

Smid, H. A., VAn Loon, J. J. A., Posthumus, M. A., and Vet, L. E. M. 2002. GC-EAG-analysis of volatiles from Brussels sprouts plants damaged by two species of Pieris caterpillars: Olfactory receptive range of a specialist and a generalist parasitoid wasp species. Chemoecology 12:169-176.

SteinberG, S., Dicke, M., and Vet, L. E. M. 1993. Relative importance of infochemicals from first 
and second trophic level in long-range host location by the larval parasitoid Cotesia glomerata. J. Chem. Ecol. 19:47-58.

Tumlinson, J. H., TuRLings, T. C. J., and Lewis, W. J. 1992. The semiochemical complexes that mediate insect parasitoid foraging. Agric. Zool. Rev. 5:221-252.

TURLINGS, T. C. J. 1990. The semiochemically mediated, host-searching behavior of the endoparasitic wasp Cotesia marginiventris (Cresson) (Hymenoptera: Braconidae). Ph.D. Dissertation. University of Florida, Gainesville.

Turlings, T. J. C., Tumlinson, J. H., and Lewis, W. J. 1990. Exploitation of herbivore-induced plant odors by host-seeking parasitic wasps. Science 250:1251-1253.

Turlings, T. J. C., Tumlinson, J. H., Heath, R. R., ProveauX, A. T., and Doolittle, R. E. 1991. Isolation and identification of allelochemicals that attract the larval parasitoid, Cotesia marginiventris. (Cresson), to the microhabitat of one its host. J. Chem. Ecol. 17:2235-2251.

Turlings, T. C. J., McCall, P. J., Alborn, H. T., and Tumlinson, J. H. 1993. An elicitor in caterpillar oral secretions that induces corn seedlings to emit chemical signals attractive to parasitic wasps. J. Chem. Ecol. 19:411-425.

Turlings, T. C. J., Loughrin, J. H., Mccall, P. J., RöSE, U. S. R., LeWis, W. J., and Tumlinson, J. H. 1995. How caterpillar-damaged plants protect themselves by attracting parasitic wasps. Proc. Natl. Acad. Sci. U.S.A. 92:4169-4174.

Turlings, T. C. J., Lengwiler, U. B., Bernasconi, M. L., and Wechsler, D. 1998. Timing of induced volatile emissions in maize seedlings. Planta 207:146-152.

Turlings, T. C. J., Alborn, H. T., Loughrin, J. H., and Tumlinson, J. H. 2000. Volicitin, an elicitor of maize volatiles in oral secretion of Spodoptera exigua: Isolation and bioactivity. J. Chem. Ecol. 26:189-202.

Vet, L. E. M., Lewis, W. J., PApaJ, D. R., and van Lenteren, J. C. 1990. A variable-response model for parasitoid foraging behavior. J. Insect Behav. 3:471-490.

WADHAMS, L. J. 1990. The use of coupled gas chromatography: Electrophysiological techniques in the identification of insect pheromones, pp. 289-298, in A. R. McCaffery and I. D. Wilson (eds.). Chromatography and Isolation of Insect Hormones and Pheromones. Plenum Press, New York.

Whitman, D. W. and ElLer, F. 1990. Parasitic wasps orient to green leaf volatiles. Chemoecology $1: 69-75$. 